\title{
PROPOSTA DE UM DISPOSITIVO PARA COMUNICAÇÃO AUMENTADA ALTERNATIVA
}

\author{
C. G. Lima Barreto*; L. R. Nóbrega*; G. L. Silva*; I. A. Marques*; F. R. Martins*; G. F. \\ Machado*; M. F. Rodrigues* E. L. M. Naves* \\ *Universidade Federal de Uberlândia, Uberlândia, Brasil \\ e-mail: lima.cglima@gmail.com
}

\begin{abstract}
Resumo: Para um bom convívio social, é necessário que as pessoas sejam capazes de transmitir informações de um modo que esta seja compreendida adequadamente. A comunicação pode ser na forma verbal, sendo esta na forma falada ou escrita, ou de forma não verbal, através de linguagens corporais. Ao diagnosticar a deficiência na comunicação de uma pessoa, é possível auxiliá-la de maneira a aumentar e/ou melhorar essa comunicação a partir da criação de dispositivos de Comunicação Aumentativa Alternativa (CAA). O objetivo deste trabalho é propor métodos para a criação de um dispositivo de CAA com design centrado no usuário, cujas principais características sejam portabilidade e baixo custo, usando como referência as tecnologias disponíveis no mercado. Foi aplicado um questionário e com os resultados concluiuse que os dispositivos utilizados pelos pacientes entrevistados não atendem totalmente suas necessidades, demonstrando a importância do desenvolvimento de um novo aparelho de CAA. Assim, espera-se que a metodologia proposta nesse estudo seja utilizada para criar um novo dispositivo de CAA que possa atender as reais necessidades dos usuários.
\end{abstract}

Palavras-chave: Comunicação, Deficiência, Comunicação Aumentativa Alternativa, Dispositivos de CAA.
Abstract: To ensure a good social life, it is necessary for people to be able to transmit information so that it can be correctly understood. Communication can be verbal, in the form of speech or writing, or nonverbal, through body language. When diagnosing the communication disability of a person, it's possible to help increase and/or improve the communication through the creation of augmented and alternative communication devices (AAC). The goal of this work is to propose a method for the creation of an AAC device with a centered-user design, in which the main characteristics are portability and low cost, using the available technologies. A questionnaire was applied and the results showed that the devices used by the interviewed patients do not fully attend their needs, showing an importance of the development of a new $A A C$ device. This way, it's expected that the proposed methodology of this study should be used to create a new AAC device that can comply with the real needs of the users.

Keywords: Communication, Disability, Augmentative Alternative Communication, AAC devices.

\section{Introdução}

Em meio a um convívio social básico, é importante que os seres humanos sejam capazes de realizar trocas de informações. Neste ponto de vista, a comunicação surge com o propósito de criar uma relação social onde um sujeito consiga transferir uma mensagem para outro de modo que seja compreendido, sem limitações. Desta forma, para que ocorra uma comunicação, é necessário que se tenha um emissor, uma mensagem, um canal e um receptor $[1,2]$. Embora a fala seja a forma de comunicação mais utilizada, existem outras maneiras de se interagir com a sociedade e a partir do momento em que, nessa interação, o receptor entenda a mensagem do emissor, existe uma comunicação [3].

Algumas doenças e/ou deficiências podem incapacitar permanentemente ou temporariamente a comunicação dos indivíduos acometidos por elas, como acidente vascular encefálico, traumatismos causados por acidentes, entre outras [4]. A inclusão de pessoas com alguma deficiência em qualquer ambiente social é um diferencial na qualidade de vida desses indivíduos [5]. A comunicação é um facilitador da vida em sociedade, e utilizar a tecnologia para estabelecer a comunicação (Comunicação Aumentada Alternativa) pode ser uma ferramenta valiosa para indivíduos com necessidades específicas, uma vez que a inserção destas pessoas no contexto social que fazem parte pode ocorrer de forma espontânea. Assim, as barreiras sociais podem ser quebradas, e os relacionamentos interpessoais e o processo educativo podem ser melhorados. [6,7].

A Comunicação Aumentada Alternativa (CAA) tem como objetivo minimizar ou substituir a deficiência de indivíduos que apresentam distúrbios na comunicação, podendo desta forma contribuir efetivamente para a independência destas pessoas [6,7]. O termo CAA tem como definição permitir a comunicação por outras formas, além da modalidade oral, como o uso de gestos, pranchas de alfabeto, sistemas sofisticados de computador, dentre outros.

Neste contexto, existe no mercado uma diversidade de dispositivos para atender este público. Entretanto nem todos suprem realmente as necessidades dos usuários. De acordo com Allen [8], para um dispositivo de CAA ser bem sucedido ele deve atender alguns itens 
básicos como: aparência, percepção, ergonomia (física, cognitiva e sensorial), aspectos psicológicos e, principalmente, as necessidades reais do usuário. $\mathrm{O}$ produto deve ter uma aparência agradável, discreta, compatível com o ambiente social com o qual o usuário interage e que não se torne obsoleta rapidamente. Os materiais táteis do dispositivo (textura e formato) devem ser de fácil manuseio para os indivíduos.

Diante deste contexto, este trabalho tem como objetivo propor o desenvolvimento de um dispositivo de CAA com design centrado no usuário, cujas principais características sejam portabilidade e baixo custo. Como referência para nortear este trabalho, utilizou-se os resultados obtidos a partir do dispositivo PCA (Portland Communication Aid) [8], as tecnologias disponíveis que se tem no mercado hoje, e outras fontes de pesquisa.

\section{Materiais e métodos}

O ponto inicial deste trabalho foi aplicar um questionário à pacientes que apresentam dificuldades na fala, de modo que fosse possível encontrar características que viabilizassem a criação de um dispositivo de CAA. A priori seriam selecionados 10 usuários que possuíam algum déficit na comunicação.

Apenas dois indivíduos participaram desta pesquisa. Um deles é portador de ELA (Esclerose Lateral Amiotrófica) e outro portador de PC (Paralisia Cerebral). Nenhum dos participantes consegue se comunicar verbalmente.

A aplicação do questionário se deu de forma presencial. Isso é vantajoso para que o pesquisador aproxime-se do usuário, de modo à extrair as necessidades reais do usuário e ter um produto final bem sucedido [9]. É válido ressaltar que as perguntas foram elaboradas considerando o nível de entendimento dos usuários de CAA.

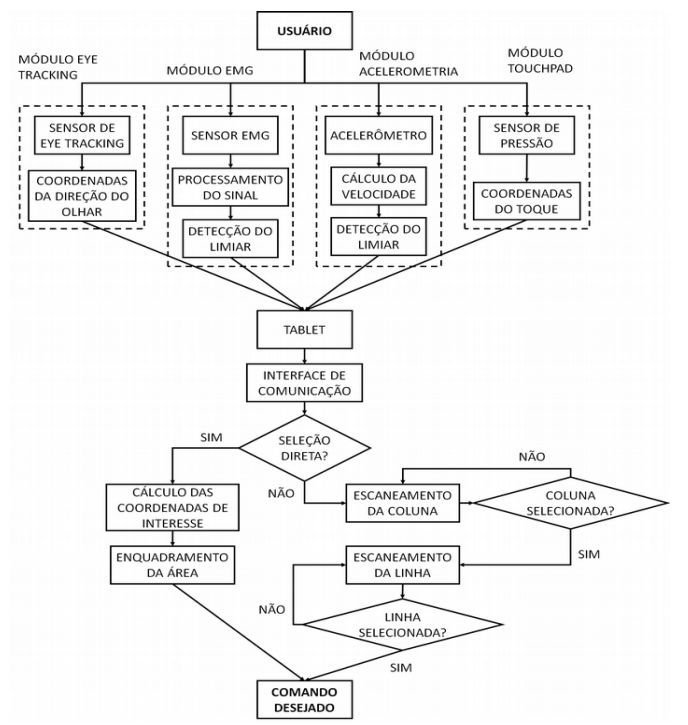

Figura 1 - Arquitetura do sistema proposto.
Após a aplicação do questionário, foi criado um diagrama para representar a arquitetura do sistema proposto, mostrado na Figura 1.

Cada um dos módulos de entrada (Módulo Touchpad, Módulo de Eye Tracking, Módulo EMG e Módulo de Acelerometria) é representado com suas respectivas etapas de processamento.

Foi realizado um estudo detalhado para escolha de cada componente desse sistema. As escolhas serão apresentadas a seguir.

\section{Resultados}

Algumas das respostas do questionário estão demonstradas na Tabela 1 . Na primeira coluna estão alguns itens do questionário, na segunda e terceira coluna estão as respostas dos entrevistados, o portador de ELA e o portador de PC, respectivamente. As demais questões abordadas no questionário estão relacionadas à preferências dos usuários, como: tamanho e cor do dispositivo, alterações na tonalidade da voz, sotaque, modelo de feedback, entre outros.

Tabela 1: Respostas dos usuários CAA.

\begin{tabular}{ccc}
\hline Item & ELA & PC \\
\hline $\begin{array}{c}\text { Usa algum } \\
\text { dispositivo de CAA? }\end{array}$ & SIM & SIM \\
$\begin{array}{c}\text { Ele atende suas } \\
\text { necessidades? }\end{array}$ & NÃO & NÃO \\
$\begin{array}{c}\text { Gostaria de usar } \\
\text { outro dispositivo de } \\
\text { CAA? }\end{array}$ & SIM & SIM \\
$\begin{array}{c}\text { Gostaria de testar } \\
\text { um novo dispositivo } \\
\text { de CAA? }\end{array}$ & SIM & \\
\hline
\end{tabular}

Após coletar os dados no questionário, verificou-se a necessidade de criar um novo dispositivo de CAA, que melhor atenda as demandas dos usuários. Diante deste resultado, este trabalho apresenta uma proposta para o desenvolvimento desse produto.

Para compor o hardware do sistema, optou-se por $\mathrm{u}$ m tablet por ser um equipamento de manuseio relativamente fácil e custos não muito elevados. Os módulos de entrada escolhidos, ou seja, os módulos para permitir a interação usuário-dispositivo são: touchpad, EMG, Eye Tracking e Acelerometria.

O Módulo Touchpad faz uso do sistema de células de carga integrados no próprio tablet como um dado de entrada, determinando a posição de interesse do usuário a partir do toque do mesmo na tela do dispositivo. $\mathrm{O}$ Módulo de Eye Tracking funciona a partir de um sensor de oculografia por infravermelho, capaz de determinar a 
posição de interesse do indivíduo em uma tela ou superfície após um rápido processo de calibração.

Já os Módulos EMG e de Acelerometria funcionam a partir de um gatilho simples. No primeiro módulo, o gatilho é a contração do músculo conectado ao sensor de eletromiografia. Para o segundo, deve ser colocado um acelerômetro no dedo do usuário, onde o movimento rápido do mesmo será detectado pelo sensor. Para ambos os casos, existe a opção de utilizar shields de microcontroladores (como o Arduino), que são capazes de detectar o gatilho com confiabilidade e possuem um custo reduzido.

A solução mais recomendada buscando um cenário multiplataforma seria o desenvolvimento de um web app, ou seja, o desenvolvimento do software dentro de um navegador. Para isso seria utilizada a linguagem JavaScript, uma linguagem web orientada a objetos voltada para programação client-side. $\mathrm{O}$ sistema pode ser desenvolvido como um web app utilizando a ferramenta Intel ${ }^{\circledR}$ XDK, que fornece um ambiente de desenvolvimento integrado com suporte às APIs dos sensores dos equipamentos dos principais fabricantes mundiais.

Quanto ao método de interação, optou-se pela determinação de dois métodos. A interação direta, que a opção desejada é selecionada diretamente, sem nenhum tipo de passo intermediário entre o processo de decisão e seleção, e interação indireta, que envolve o uso de switchs ou gatilhos, e uma forma de escaneamento de opções, que são realçadas de forma cíclica, de forma que quando o usuário deseja escolher determinada opção, ele ativa dito gatilho.

Os módulos que fazem uso do método de seleção direta são o Módulo de Eye Tracking e Touchpad. Os módulos que fazem uso do método de seleção indireta no sistema proposto são o Módulo de Acelerometria e EMG.

A interface deve ser baseada no software EDiTH, uma tecnologia assistiva que integra várias opções de comunicação (leitura e escrita de texto, manipulação de arquivos, frases de contexto, entre outras). É também uma ferramenta que permite a análise em tempo real da interação entre um usuário com deficiência e o software. A Figura 2 representa o modelo de possível interface do software.

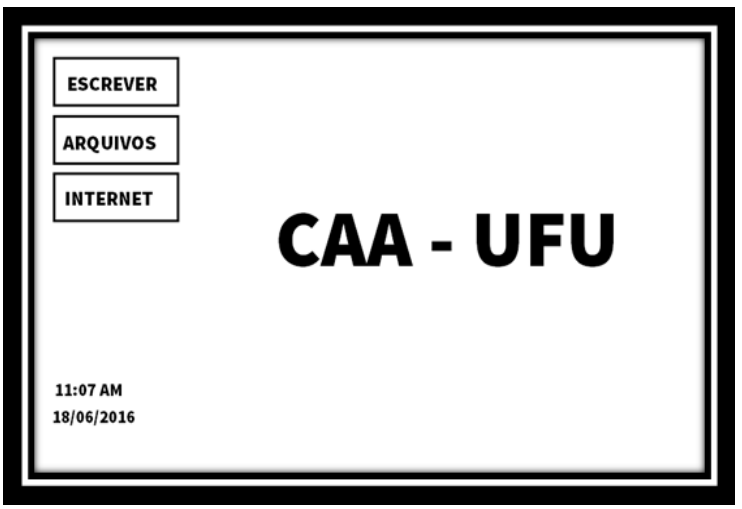

Figura 2: Proposta de interface principal do módulo de comunicação.
A fim de se atender aos requisitos de software do dispositivo CAA, o foco das opções para o usuário seria na comunicação direta (falar/escrever, associados a um modelo TTS ou Text-to-Speech) e na manipulação de arquivos e internet (arquivos de música, vídeo, fotos e documentos de texto).

Caso o usuário selecione a opção para escrita, deverá apresentar a opção de escrita em teclado virtual (com lista de prováveis palavras baseada em informações de contexto). Pensando-se em uma comunicação verbal, à saída do módulo de comunicação será incorporado um módulo TTS, de forma que o que estiver escrito no documento será pronunciado em voz alta, se o usuário assim desejar. As características da voz poderão ser configuradas de acordo com as opções disponíveis em cada região.

Além da opção de escrita, o usuário terá como opção selecionar frases contextuais, pré-preparadas para cada um dos possíveis contextos no qual o usuário esteja inserido. Essas frases podem ser customizadas de acordo com a preferência e o conhecimento do usuário, e novos grupos sempre poderão ser adicionados e reorganizados para se adaptar às possíveis situações no qual o mesmo esteja inserido.

Uma última opção (ainda não existente no EDiTH) seria a comunicação por meio de figuras, baseada no princípio de placas de comunicação tradicionais, para usuários que sejam analfabetos ou que possuam alguma dificuldade cognitiva no reconhecimento dos caracteres de comunicação. Seguindo o mesmo princípio do módulo de escrita, a placa seria apresentada na interface para escolha de um desenho específico, dependendo do método de entrada que esteja sendo utilizado. Assim como no caso do módulo de frases prontas, o usuário poderá customizar a organização e conteúdo das figuras de acordo com sua preferência, tornando-se também uma ferramenta contextual a ser utilizada de acordo com o contexto do usuário.

Além desses três métodos de comunicação direta, uma opção de escolha dentro da solução de software é a de manipulação de arquivos. Pensando nas principais opções de mídia, o sistema deverá oferecer suporte para execução de arquivos de áudio (músicas, por exemplo), imagens ou fotos, vídeos e documentos de texto (livros, arquivos PDF ou outros documentos).

Por fim, a última opção requerida para o módulo de comunicação do tablet seria o acesso à internet, para pesquisa e navegação casual. Em função das limitações dos métodos de seleção indireta, um arranjo alternativo deve ser dado ao controle do cursor durante a navegação na internet.

\section{Discussão}

Ao observar a Tabela 1 é possível perceber que ambos os voluntários entrevistados já possuem um dispositivo de CAA, porém sentem a necessidade de um novo, que atenda melhor suas necessidades, o que é proposto nesse estudo. Percebe-se também que estão 
dispostos a ajudar no desenvolvimento deste dispositivo por meio da participação de testes.

A escolha pelo tablet como hardware proposto torna o projeto viável, uma vez que tem um valor final acessível e permite a montagem sem depender de grandes indústrias. Além disso, a disponibilidade do mercado desse equipamento permite abranger um maior número de potenciais usuários.

O sistema modular entre os métodos de entrada é altamente customizável e permite grande flexibilidade para se ajustar às necessidades de um usuário específico. Unido a isso, a linguagem JavaScript tem a possibilidade de ser multiplataforma, ou seja, capaz de se executar nos três sistemas operacionais mais comuns (Windows RT, o iOS e o Android) sem que haja grande necessidade de alteração em código ou interface. Dessa forma, facilita a escolha de um tablet que seja compatível.

Os métodos de interação por seleção direta e indireta levam em consideração os inúmeros graus e particularidades de cada deficiência. E o fato de as características de voz poderem ser configuradas é vantajoso para que o usuário possa escolher a identidade de sua voz. Mesmo que não seja uma necessidade básica para a comunicação, a escolha de sotaque e tonalidade da voz influencia no psicológico do paciente. Além disso, as frases pré-preparadas também são desejadas, pois agilizam a comunicação em situações onde o contexto é conhecido.

A escolha de arquivos multimídia e a possibilidade de conectar à internet, embora não estejam ligadas à comunicação direta em si (como o módulo de escrita), fazem-se importantes em uma situação de diálogo convencional, pois o uso de imagens ou mesmo vídeos pode simplificar muito a transmissão de uma ideia por parte do usuário, melhorando a taxa de comunicação sem aumentar a fadiga do mesmo pelo uso do sistema.

\section{Conclusão}

A ideia central desta pesquisa é a possibilidade de se desenvolver um dispositivo que seja capaz de atender ao maior número de usuários de CAA possível, sem sacrificar a funcionalidade ou exigir um alto investimento para aquisição por parte do usuário, além de permitir um alto grau de personalização em relação às preferências e necessidades do mesmo.

Sabe-se que para uma boa aceitação do dispositivo pelo usuário CAA e pela sua família, é necessário que se estabeleça um meio de comunicação eficiente, facilitando o processo de inclusão e melhora na qualidade de vida do indivíduo. Deste modo, a CAA é a protagonista em estabelecer a relação entre o indivíduo e a sociedade, viabilizando ações comunicativas e tornando o sujeito ativo nas relações interpessoais [10].

Ao final desta pesquisa, conclui-se que o dispositivo de CAA proposto possuirá uma aparência comum e discreta e, principalmente, será capaz de atender as necessidades reais dos indivíduos. Tudo isso por meio de combinações de tecnologias já existentes no mercado.

\section{Agradecimentos}

Agradecemos à FAPEMIG, CAPES e CNPq por tornarem possível a realização dessa pesquisa.

\section{Referências}

[1] Parry, John. Psicologia da comunicação humana. Cultrix, 1976.

[2] Silva, Lúcia Marta Giunta da et al. Comunicação não-verbal: reflexões acerca da linguagem corporal. Revista latino-americana de enfermagem, v. 8, n. 4, p. 52-58, 2000.

[3] Magalhães, Carla Sofia Cerqueira. Comunicação sem palavras. 2010. Tese de Doutorado. Universidade da Beira Interior. Covilhã, Setembro 2010. Portugal.

[4] Soares, Jones Adão Pereira et al. Desenvolvimento de uma ajuda técnica informática para o processo de comunicação aumentativa. 2002.

[5] Piovesan, D. S.; Medina, D. R.; Passerino, L. Sistema de Comunicação Alternativa para Inclusão de Pessoas com Deficiência no Mercado de Trabalho. In: Proceedings of the 5th Brazilian Congress of Augmentative and Alternative Communication. 2013. p. 105-110.

[6] Garbin, Tânia Rossi; Dainese, Carlos Alberto. AmCara-Ambiente e Comunicação Alternativo com Realidade Aumentada: $\mathrm{O}$ acesso do deficiente motor severo a softwares e Web. In: Anais do Simpósio Brasileiro de Informática na Educação. 2009.

[7] Bersch, Rita. Introdução à tecnologia assistiva. Porto Alegre: CEDI, 2008.

[8] Allen, Jonathon. Some problems of designing for augmentative and alternative communication users: an enquiry through practical design activity. 2002. Tese de Doutorado. (C) Jonathon Allen.

[9] Peters, Betts et al. Soliciting BCI user experience feedback from people with severe speech and physical impairments. Brain-Computer Interfaces, v. 3, n. 1, p. 47-58, 2016

[10] Zaporoszenko, A. et al. Comunicação Alternativa E Paralisia Cerebral: recursos didáticos e de expressão. Brasília/DF, 2008.

[11] Mendes, Adriana et all. A efetividade e aceitabilidade da comunicação alternativa e/ou aumetantiva em crianças com neuropatia crônica não progressiva - Rumo à inclusão. Anais de Congresso. IV Seminário Internacional Sociedade Inclusiva. PUC Minas Gerais. Belo Horizonte. 2006. 